\title{
Motor Management of Permanent Magnet Synchronous Machines
}

\author{
Anton Haumer Christian Kral \\ AIT Austrian Institute of Technology $\mathrm{GmbH}$ \\ Giefinggasse 2, 1210 Vienna, Austria \\ a.haumer@haumer.at christian.kral@ait.ac.at
}

\begin{abstract}
In this paper the principle of loss and current related motor management of permanent magnet synchronous machines is demonstrated. For this purpose a simplified Modelica model of an interior permanent magnet machine synchronous machine drive is presented. In this model copper, core and friction losses are considered. Simulations then used to determine operating points of minimum current demand and losses, respectively. Based on simulation results some basic insights into motor management are presented. General aspects of motor management modeling are then discussed.
\end{abstract}

Keywords: Permanent Magnet Synchronous Machine, Field Oriented Control, Optimization of Field Current

\section{Introduction}

Due to the rising demand on mobility together with contradictions such as climate change and scarce resources a rising variety of electric and hybrid electric vehicles is currently offered. For such vehicles high torque densities and efficiencies of the electric drive are demanded. In particular the total losses of the electric drive shall be as low as possible considering a given derive cycle.

Nowadays, three types of electric machines are commonly used:

- induction machine with squirrel cage

- electrically excited synchronous machines

- permanent magnet (PM) synchronous machine

Typically, asynchronous induction machines are very reliable due to the robust design of the squirrel cage.
However, they need a magnetizing current component to excite the magnetic field. Electrically excited synchronous machines have a separate field winding in the rotor which - for vehicle applications - is usually supplied through slip rings. For induction and electrically excited synchronous machines, additional copper losses arise due to the currents required for exciting magnetic field. In permanent magnet synchronous machines the magnetic field is mainly excited by the permanent magnets. Rare earth magnets have a high energy density and show thus a very high torque and power density.

In the base speed range of either machine, voltage is more or less linearly proportional to speed. Since the voltage is limited by the available battery voltage, higher speeds can only be realized by reducing the magnetic field in the machine - this is the field weakening range. In induction and electrically excited synchronous machines this measure is performed by reducing the field current. In permanent magnet synchronous machines, the permanent magnets cannot be switched off. In order to yet operate the machine in the field weakening range, a current component has to be controlled such way that it counteracts the field caused by the permanent magnet.

For all kinds of machines, one and the same mechanical operating point can be accomplished by different combinations of field and torque generating current components. So obviously, there exists a certain potential of operating an electric drive such way that the total current or losses, respectively, are as low as possible $[1,2,3]$. In this paper the case of a permanent magnet synchronous machine drive is investigated in order to reveal some basic insights on optimal motor management [4].

In particular, the two optimization cases are investigated. First, minimum losses of the machine are examined, since low losses represent a high efficiency of 
the machine and thus enable higher energy utilization. Second, minimum current are investigated, since the maximum current is limited by the power electronics and current also influences the total losses of the power converter.

\section{Field Oriented Control of PM Ma- chine}

The functional principles of induction and synchronous machines are the same: if we feed three sinusoidal currents $i_{1}, i_{2}$ and $i_{3}$ with a time phase shift of $120^{\circ}$ to three windings in the stator that are spaced by $120^{\circ}$ at the circumference, we achieve a magnetic field wave in the air gap of constant amplitude, rotating with an angular velocity dependent on the frequency of the currents. The rotating magnetic field can be represented by a complex current space phasor,

$$
\underline{i}=\frac{2}{3}\left(i_{1}+\underline{a} i_{2}+\underline{a}^{2} i_{3}\right)
$$

where

$$
\underline{a}=e^{\mathrm{j} \frac{2 \pi}{3}}
$$

The zero component

$$
i_{0}=\frac{1}{3}\left(i_{1}+i_{2}+i_{3}\right)
$$

is usually avoided by normal drive designs since it has no effect on power exchange with the rotor. The current space phasor (1) and the zero component (3) can be interpreted as a linear transformation of the three winding current $i_{1}, i_{2}$ and $i_{3}$. Rotating the current space phasor (1) into a rotor fixed coordinate frame, it can be represented by current components of the $d$ and $q$ axis,

$$
\underline{i}^{r}=\underline{i} e^{-\mathrm{j} \gamma}=i_{d}+\mathrm{j} i_{q},
$$

see Fig. 1, where $\gamma$ is the angle between stator and rotor frame. The space phasor transformation can be applied to voltages and flux linkages as well to model the machine behavior. The flux linked with the stator winding can be determined by

$$
\underline{\Psi}=\Psi_{\mathrm{PM}}+L_{m d} i_{d}+\mathrm{j} L_{m q} i_{q},
$$

see Fig. 2, where the flux of the permanent magnet, $\Psi_{\mathrm{PM}}$, is aligned with the $d$ axis.

The number of pole pairs, $p$, is defined by the repetition of the stator winding along the circumference. Since the rotor is equipped with a permanent magnet

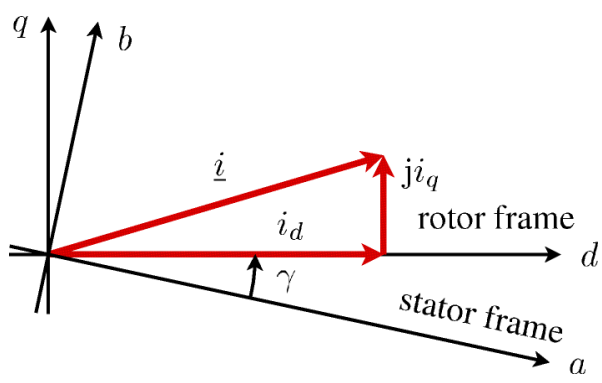

Figure 1: Transformation for the current phasor from the stator to the rotor frame, considering the transformation angle $\gamma$

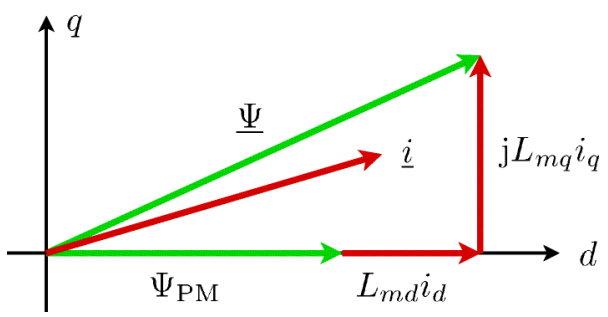

Figure 2: The total stator flux linkage phasor $\underline{\Psi}$ is composed of the flux of the magnet $\Psi_{\mathrm{PM}}$ and the inductive components due the total main inductance and current components

arrangement showing the same number of pole pairs, it is evident that the rotor will try to align in the rotating magnetic field. Thus it is useful to decompose the stator current space phasor into a component aligned with the rotor poles, $i_{d}$, and a perpendicular component, $i_{q}$ (pointing to the pole gap). Having information about the rotor orientation - and therefore about the field orientation - it is possible to control the field current $i_{d}$ and the torque generating current $i_{q}$ independent from each other - similar as in DC machines.

\subsection{Torque Generation}

The electromagnetic torque generated in the air gap of a PM machine is a reaction between magnetic flux linked with the stator winding, $\Psi$, and the conjugate complex current space phasor:

$$
\tau_{e l}=-\frac{3 p}{2} \operatorname{Im}\left(\underline{\Psi} \underline{i}^{*}\right)
$$

Taking into account the nature of the permanent magnet synchronous machine with different magnetic conductances in the direction of the poles ( $d$-axis) and in direction of the pole gaps ( $q$-axis), we obtain:

$$
\tau_{e l}=\frac{2 p}{3}\left(\Psi_{\mathrm{PM}} i_{q}+\left(L_{m d}-L_{m q}\right) i_{d} i_{q}\right)
$$


In this equation, $L_{m d}$ and $L_{m q}$ are the total main inductances in the $d$ and $q$ axis, respectively, representing the magnetic reluctances of these axes. For magnetically isotropic machines with $L_{m d}=L_{m q}$ the electromagnetic torque is directly proportional to the product of the magnetic flux linkage of the permanent magnet, $\Psi_{\mathrm{PM}}$, and the current in the $q$ axis. The permeability of permanent magnets is almost equal to air. Thus, magnetically isotropic machines typically have the magnets mounted on the surface of the rotor, see Fig. 3a.

It is evident from (7) that for machines with different magnetic reluctances in $d$ and $q$ axis an additional torque component arises - the reluctance torque. This torque component is proportional to the product of the $d$ and $q$ axis current and the difference between the inductances of the $d$ and $q$ axis. An anisotropic rotor configuration is shown in Fig. $3 \mathrm{~b}$ interior permanent magnets. In order to gain a higher reluctance torque it is desirable to make the difference between the inductances of the $d$ and $q$ axis as large as possible.

Even though surface mounted permanent magnet synchronous machine reveal a certain potential for minimizing losses $[5,6]$, the potential is much higher in case of interior mounted permanent magnet synchronous machines $[7,8,9,10,11]$.

\subsection{Losses}

In order to minimize current consumption or losses, respectively, the total losses of the PM machine have to be taken into account. For the investigated machine, ohmic losses, core losses and friction losses are considered.

Ohmic losses (copper losses) are directly proportional to the total stator winding resistance, $R_{s}$, and the sum of the squared winding currents,

$$
P_{\mathrm{Cu}}=R_{s}\left(i_{1}^{2}+i_{2}^{2}+i_{3}^{2}\right)=\frac{3}{2} R_{s} \underline{i}_{s} \underline{i}_{s}^{*} .
$$

Core losses are usually separated into eddy current losses and hysteresis losses [12, 13]. Some models even take excess losses into account, but these losses are usually inherently considered by the eddy current loss model. In the presented paper machine models of the Modelica Standard Library (MSL) 3.2 are used, so hysteresis losses are not taken into account. The total core losses are thus modeled dependent on the voltage induced by the flux $\Psi$, linked with the stator winding,

$$
P_{c}=\frac{3}{2} G_{c}\left(\frac{\mathrm{d} \Psi}{\mathrm{d} t}\right)^{2} .
$$



(a) surface magnets

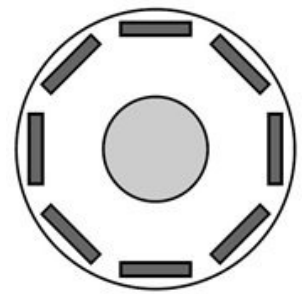

(b) interior magnets
Figure 3: Permanent magnet rotor configurations

Friction torque is modeled as a power of rotor speed represented by parameter $a_{f}$. Friction losses are thus determined by

$$
P_{f}=P_{f, \text { ref }}\left(\frac{\Omega}{\Omega_{\mathrm{ref}}}\right)^{a_{f}+1},
$$

where $\Omega$ is the mechanical angular rotor speed and index ref indicates a reference point.

Due to the great dependency of torque from the current components $i_{d}$ and $i_{q}$ in (7), a high potential for saving current and losses, respectively, is obvious.

\subsection{Voltage Induction}

The induced voltage under stationary operating conditions is given by

$$
\underline{v}=\mathrm{j} \omega \underline{\Psi}=\mathrm{j} \omega\left(\Psi_{\mathrm{PM}}+L_{m d} i_{d}\right)-\omega L_{m q} i_{q} .
$$

For zero current in the $q$ axis, the induced voltage solely depends on the flux linkage due to the permanent magnet and the current of the $d$ axis and the electrical angular speed,

$$
\omega=\frac{\Omega}{p} .
$$

For zero current in both axes the induced voltage rises linearly with speed $\omega$. When the induced voltage exceeds the maximum voltage, determined by the available battery voltage, the field has to be weakened in order to further increase speed. This can be achieved by injecting a negative $d$ axis current component which reduces the total flux linked with the stator winding, see (5).

\section{Modelica Model of the Drive}

Fig. 4 shows the Modelica model used for investigating the motor management of the drive. A permanent magnet synchronous machine model - taken from the 


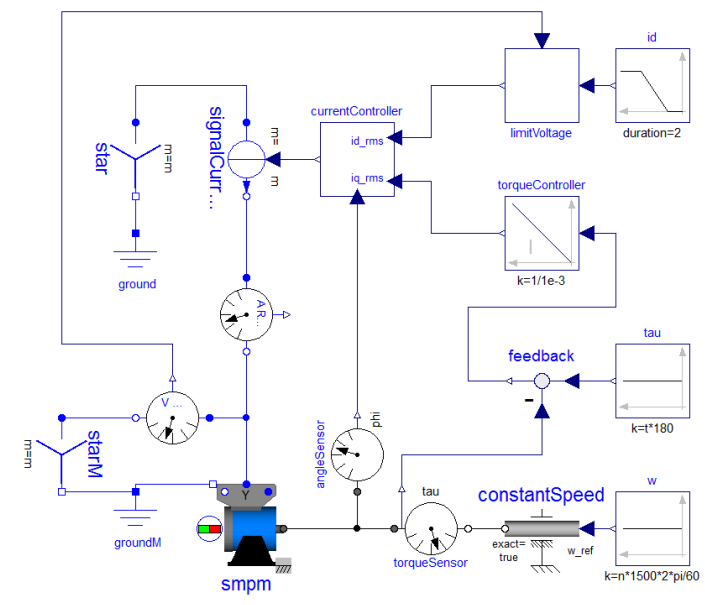

Figure 4: Modelica model of the drive

MSL 3.2 - is fed by a signal current source. This simplification represents an idealized supply case without modeling the details of a power inverter. This way pulse width modulation (PWM) specific effects are not taken into account, since the reference values of the $d$ and $q$ axis current are directly injected into the machine after an inverse space phasor transformation, i.e., calculating the instantaneous three phase currents (block currentController).

The shaft of the machine is coupled by an ideal speed source. An angle sensor is used to feed back the angle between stator and rotor frame, $\gamma$, to the inverse space phasor transformation.

The field exciting current, $i_{d}$, is varied linearly within a given range; the block limitVoltage ensures that the actual terminal voltage does not exceed the available DC voltage source, representing the battery voltage of an electric or hybrid electric vehicle. The $q$ current component is determined by a integral controller which is fed by the difference between desired and actual torque. The integral time of this controller is very small such that control specific effects are negligible in the performed investigation.

A certain point of operation as well as the range for optimization are determined by

- torque,

- speed, and

- the range for varying the current component $i_{d}$.

Output variables of the investigated model are the total current consumption and the total machine losses. In the presented paper the optimum point of operation is determined manually by either varying speed or

\begin{tabular}{lcc} 
parameter & value & unit \\
\hline number of pole pairs & & \\
nominal frequency & 50 & $\mathrm{~Hz}$ \\
nominal RMS voltage per phase & 100 & $\mathrm{~V}$ \\
nominal RMS no load voltage per phase & 75 & $\mathrm{~V}$ \\
nominal torque & 180 & $\mathrm{Nm}$ \\
nominal stator resistance per phase & 0.03 & $\Omega$ \\
nominal stator stray reactance per phase & 0.1 & $\Omega$ \\
nominal main reactance per phase, $d$ axis & 0.3 & $\Omega$ \\
nominal main reactance per phase, $q$ axis & 0.6 & $\Omega$ \\
nominal core losses & 500 & $\mathrm{~W}$
\end{tabular}

Table 1: Machine parameters used for the analysis of the motor management

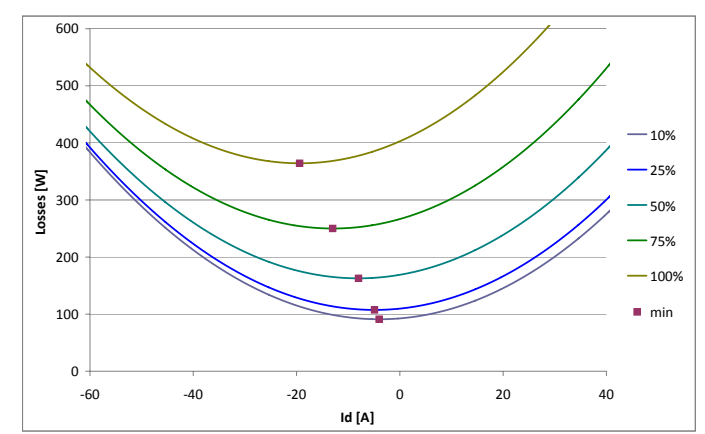

Figure 5: Losses at 25\% nominal torque, motor operation, speed variation 10-25-50-75-100\% nominal speed

torque, and fixing the remaining parameters and variables, respectively. This way characteristic curves are obtained, see section 4 . The machine parameters used for the analysis are presented in Tab. 1.

\section{Simulation Results}

In this chapter simulation results at different loads, both for motor and generator operation, and different speeds at varying direct axis current are summarized. The optimal $d$ axis currents for minimal machine losses is indicated in the figures.

Fig. 5 shows at $25 \%$ nominal torque - motor operation - that machine losses rise with rising speed, due to the increase of core losses. Fig. 6 extends the trend to field weakening. Since only eddy current losses are taken into account, core losses are nearly constant. Decreasing the $q$ axis current demand (limitation of torque proportional to the inverse of speed) decreases copper 


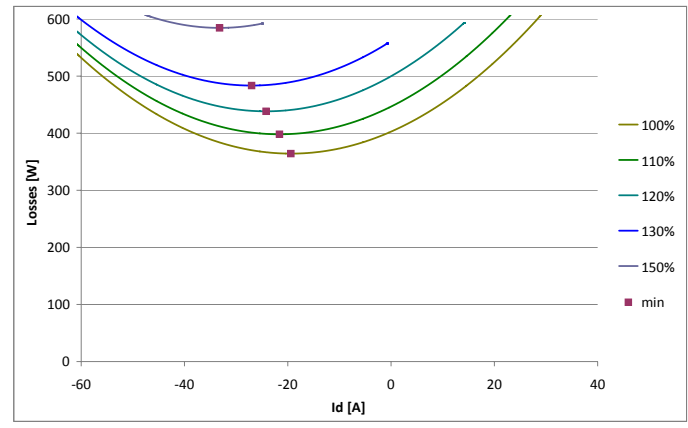

Figure 6: Losses at 25\% nominal torque, motor operation, speed variation 100-110-120-130-150\% nominal speed

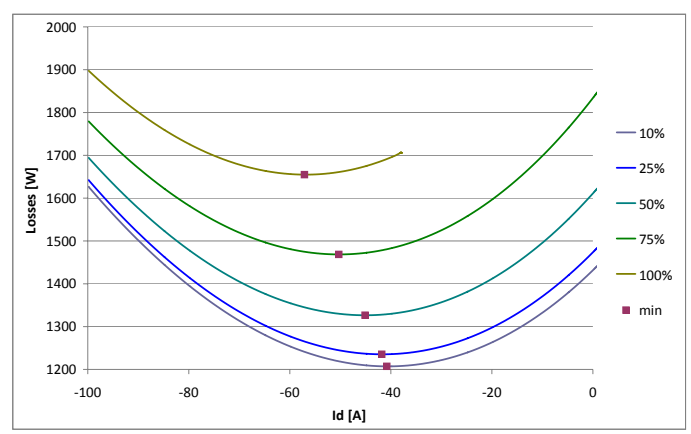

Figure 7: Losses at 100\% nominal torque, motor operation, speed variation 10-25-50-75-100\% nominal speed

losses, whereas increasing the $d$ axis current - in order to limit the stator voltage - increases copper losses. The trend depends strongly on the actual machine parameters, i.e., inductances and reference losses.

Fig. 7 and Fig. 8 show the same dependencies, but at $100 \%$ nominal torque - motor operation. Since for higher torque demand and therefore higher current the influence of copper losses is higher, losses decrease in the field weakening region with rising speed. Additionally it can be observed that a variation of the $d$ axis current is limited by the need of field weakening to avoid exceeding the voltage limit.

Fig. 9 and Fig. 10 depict the same dependencies at $100 \%$ nominal torque, but for generator operation, with only small differences compared to motor operation.

Additionally to determining the optimal $d$ axis current for minimum machine losses, minimum total cur-

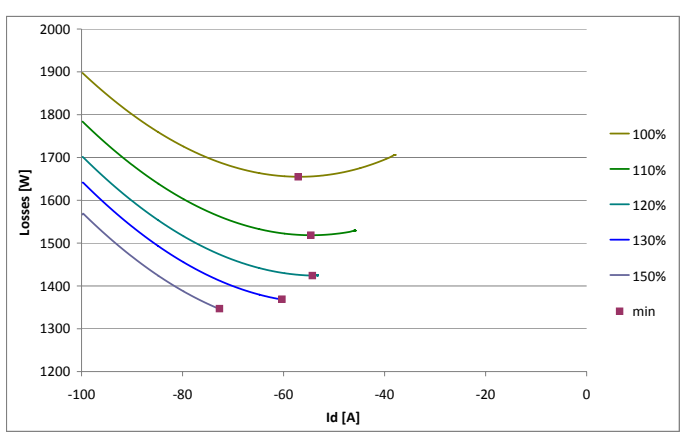

Figure 8: Losses at 100\% nominal torque, motor operation, speed variation 100-110-120-130-150\% nominal speed

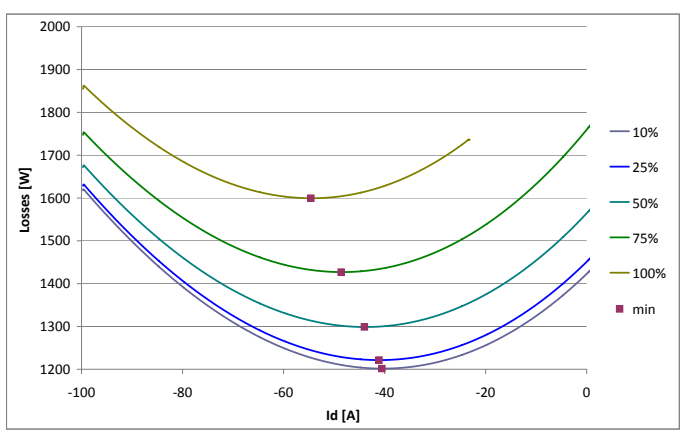

Figure 9: Losses at 100\% nominal torque, generator operation, speed variation 10-25-50-75-100\% nominal speed

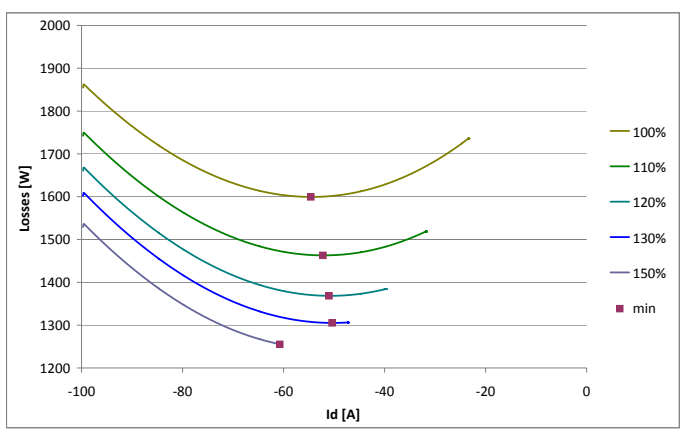

Figure 10: Losses at $100 \%$ nominal torque, generator operation, speed variation 100-110-120-130-150\% nominal speed 


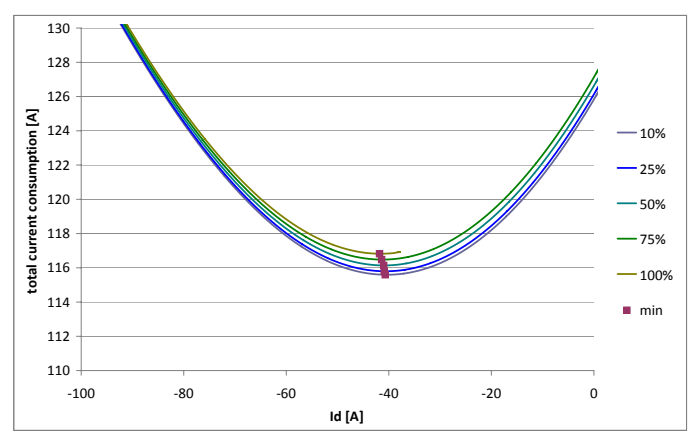

Figure 11: Total current consumption at $100 \%$ nominal torque, motor operation, speed variation 10-25-50$75-100 \%$ nominal speed

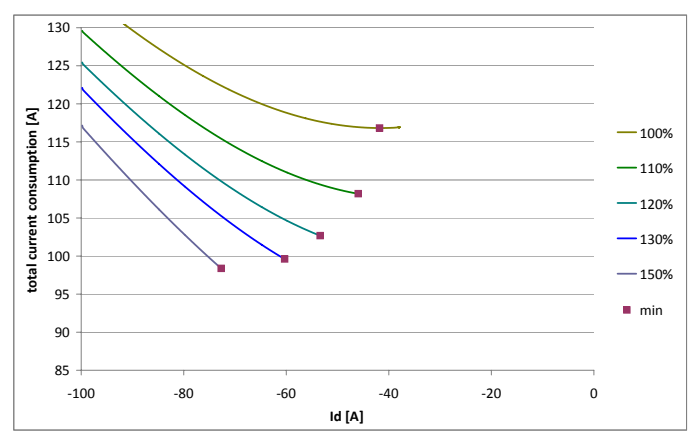

Figure 12: Total current consumption at $100 \%$ nominal torque, motor operation, speed variation 100-110120-130-150\% nominal speed

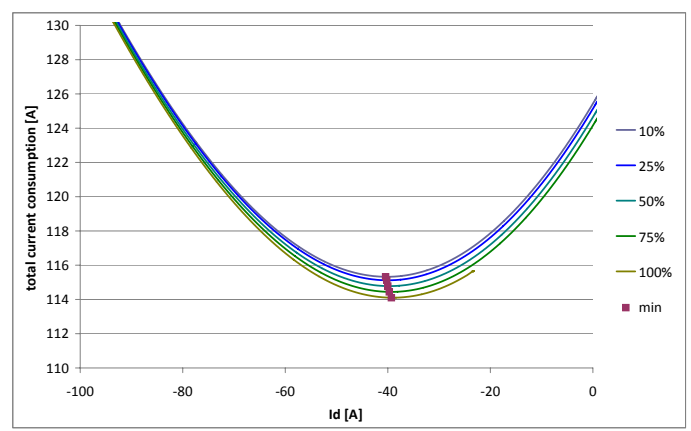

Figure 13: Total current consumption at $100 \%$ nominal torque, generator operation, speed variation 10-2550-75-100\% nominal speed

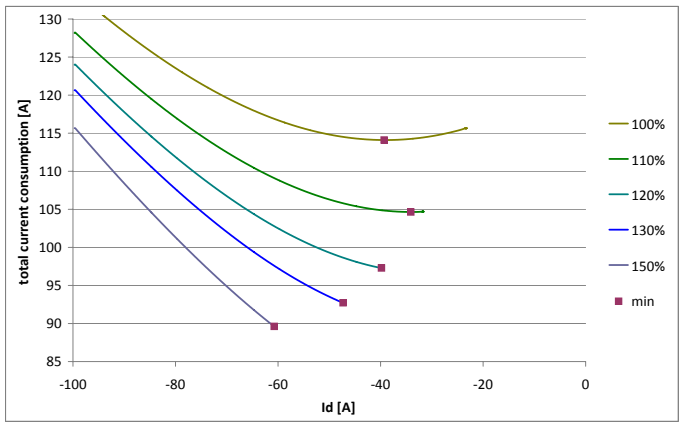

Figure 14: Total current consumption at $100 \%$ nominal torque, generator operation, speed variation 100110-120-130-150\% nominal speed

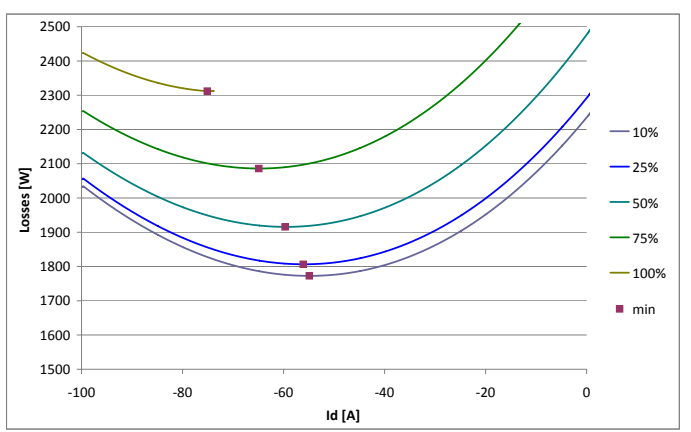

Figure 15: Losses at $125 \%$ nominal torque, motor operation, speed variation 10-25-50-75-100\% nominal speed

rent is analyzed. The total current consumption for $100 \%$ nominal torque in motor operation is depicted in Fig. 11, showing increasing total current for rising speed. This is due to the fact that losses - including rising core losses - have to be covered by electric active power consumption. For the field weakening region - depicted in Fig. 12 - decreasing losses lead to decreasing electric power consumption and therefore decreasing current consumption.

Fig. 13 and Fig. 14 show the same dependencies at $100 \%$ nominal torque, but for generator operation. The main difference compared with motor operation results from the fact that core losses cause a braking torque, which reduces the demand for electric torque. In the region of constant magnetic field this leads to decreasing current demand at rising speed.

Fig. 15 shows at $125 \%$ nominal torque - overload motor operation - that machine losses rise with rising 




Figure 16: Losses at $125 \%$ nominal torque, motor operation, speed variation 100-110-120-130-150\% nominal speed

speed, due to the increase of core losses. Fig. 16 extends the trend to field weakening. For speed above nominal speed a high $d$ axis current demand can be noticed. The optimum for each speed can be found at the minimum $d$ axis current that is sufficient to limit stator voltage.

\section{Discussion}

The presented simulation results rely on a simplified model of a permanent magnet synchronous machine. Based on the obtained results, one could implement an interpolation table, for controlling the optimum $d$ and $q$ axis current in a real application. In this case for a particular speed, torque and available battery voltage, the optimum $d$ and $q$ axis currents have to be precalculated and stored in such interpolation table.

However, in a real drive application, some even more complex effects arise which have to be considered properly. In the following the most relevant effects are be discussed:

- The main field inductances are non-linearly dependent on currents due to the saturating characteristic of the core [14]. Additionally, the flux contributions with respect to the $d$ and $q$ axis are not fully magnetically decoupled as suggested in (5). Therefore, cross saturation effects may have to be taken into account [15].

- The ohmic losses are temperature dependent. In order to correctly estimate ohmic losses or the optimal $d$ and $q$ axis currents, temperature has to be either measured or estimated. Temperature, however, complicates setting the optimum operating point in an online application, since an additional dimension of variability - for picking the optimum $d$ and $q$ axis currents - is added.

- In a real application, the contribution of hysteresis loss may have a significant impact on the exact total core losses. However, this is can be accomplished by modifying the core loss equation (9) according to [13].

- In the proposed model, eddy current losses of the permanent magnets are not taken into account. Such losses most likely have to be considered in a real application, sometimes even if the magnets are segmented [16].

- The PWM supply of the power inverter gives rise to certain voltage harmonics which in turn influence the total core losses. In the proposed eddy current model high frequency skin effects with respect to the core flux are not taken into account. However, in particular, PWM related voltage harmonics give rise to additional hysteresis losses due to minor hysteresis loops [17].

- More precisely, in order to maximize the total efficiency of an electric or hybrid electric vehicle, the total losses of the machine and the power converter and the battery have to be minimized, considering all actual current limits and temperatures. In particular the system optimization is a great challenge due the interdependency of the individual losses from the control variables and the (time dependent) limits.

\section{Conclusions}

The concept of optimizing the field current or the losses of an anisotropic permanent magnet synchronous machine has been demonstrated using a simplified Modelica model. Simulation results have been presented for the base speed and the field weakening region. In the performed investigations the maximum available voltage of the battery is taken into account. Limitations of the presented model are discussed and compared to real drive applications.

\section{References}

[1] S. Morimoto, Y. Tong, Y. Takeda, and T. Hirasa, "Loss minimization control of permanent magnet synchronous motor drives," Industrial Electronics, IEEE 
Transactions on, vol. 41, no. 5, pp. $511-517$, oct 1994.

[2] S. Shinnaka and T. Sagawa, "New optimal current control methods for energy-efficient and wide speedrange operation of hybrid-field synchronous motor," Electric Machines and Drives, 2005 IEEE International Conference on, pp. 535 -542, may 2005.

[3] M. Cao and N. Hoshi, "Electrical loss minimization strategy for interior permanent magnet synchronous motor drives," Vehicle Power and Propulsion Conference (VPPC), 2010 IEEE, pp. 1 -6, sept. 2010.

[4] R. F. Schiferl and T. A. Lipo, "Power capability of salient pole permanent magnet synchronous motors in variable speed drive applications," IEEE Transactions on Industry Applications, vol. 26, no. 1, pp. 115-123, January/February 1990.

[5] C. Mademlis, J. Xypteras, and N. Margaris, "Loss minimization in surface permanent-magnet synchronous motor drives," IEEE Transactions on Industrial Electronics, vol. 47, no. 1, pp. 115-122, February 2000.

[6] J.-J. Chen and K.-P. Chin, "Minimum copper loss flux-weakening control of surface mounted permanent magnet synchronous motors," IEEE Transactions on Power Electronics, vol. 18,4, pp.929-936, 2003.

[7] C. Mademlis and N. Margaris, "Loss minimization in vector-controlled interior permanent-magnet synchronous motor drives," Industrial Electronics, IEEE Transactions on, vol. 49, no. 6, pp. 1344 - 1347, dec 2002.

[8] C. Mademlis, I. Kioskeridis, and N. Margaris, "Optimal efficiency control strategy for interior permanentmagnet synchronous motor drives," Energy Conversion, IEEE Transactions on, vol. 19, no. 4, pp. 715 723, dec. 2004.

[9] S. Vaez-Zadeh, M. Zamanifar, and J. Soltani, "Nonlinear efficiency optimization control of ipm synchronous motor drives with online parameter estimation," Power Electronics Specialists Conference, 2006. PESC '06. 37th IEEE, pp. 1 -6, june 2006.

[10] S. Shinnaka and T. Sagawa, "New optimal current control methods for energy-efficient and wide speedrange operation of hybrid-field synchronous motor," IEEE Transactions on Industrial Electronics, vol. 54, no. 5, pp. 2443-2450, October 2007.

[11] M. Cao, "Online loss minimization control of ipmsm for electric scooters,” pp. 1388 -1392, june 2010.

[12] C. P. Steinmetz, "On the law of hysteresis," Proceedings of the IEEE (reprint of the American Institute of Electrical Engineers Transactions, vol. 9, pp. 3-64, 1892), vol. 72, no. 2, pp. 197-222, 1984.
[13] D. Lin, P. Zhou, W. Fu, Z. Badics, and Z. Cendes, "A dynamic core loss model for soft ferromagnetic and power ferrite materials in transient finite element analysis," Conference Proceedings COMPUMAG, 2003.

[14] C. Jo, J.-Y. Seol, and I.-J. Ha, "Flux-weakening control of ipm motors with significant effect of magnetic saturation and stator resistance," Industrial Electronics, IEEE Transactions on, vol. 55, no. 3, pp. 1330 -1340 , march 2008.

[15] P. Guglielmi, M. Pastorelli, and A. Vagati, "Crosssaturation effects in IPM motors and related impact on sensorless control," IEEE Transactions on Industry Applications, vol. 42, pp. 1516-1522, 2006.

[16] K. Yamazaki and A. Abe, "Loss analysis of interior permanent magnet motors considering carrier harmonics and magnet eddy currents using 3-d FEM," IEEE International Electric Machines \& Drives Conference, vol. 2, pp. 904-909, May 2007.

[17] Z. Gmyrek, A. Boglietti, and A. Cavagnino, "Estimation and analysis of iron losses in induction motors under sinusoidal and pwm excitation," Electrical Machines, 2008. ICEM 2008. 18th International Conference on, pp. $1-6$, sept. 2008. 